\title{
The quality of lymph node harvests in extralevator abdominoperineal excisions
}

\author{
Ben Liu* (i) and Ja'Quay Farquharson
}

\begin{abstract}
Background: Lymph node ( $L N)$ harvest in colorectal cancer resections is a well-recognised prognostic factor for disease staging and determining survival, particularly for node-negative (NO) diseases. Extralevator abdominoperineal excisions (ELAPE) aim to prevent "waisting" that occurs during conventional abdominoperineal resections (APR) for low rectal cancers, and reducing circumferential resection margin (CRM) infiltration rate. Our study investigates whether ELAPE may also improve the quality of LN harvests, addressing gaps in the literature.

Methods: This retrospective observational study reviewed 2 sets of 30 consecutive APRs before and after the adoption of ELAPE in our unit. The primary outcomes are the total LN counts and rates of meeting the standard of 12-minimum, particularly for those with node-negative disease. The secondary outcomes are the CRM involvement rates. Baseline characteristics including age, sex, laparoscopic or open surgery and the use of neoadjuvant chemoradiotherapy were accounted for in our analyses.

Results: Median LN counts were slightly higher in the ELAPE group (16.5 vs. 15). Specimens failing the minimum 12 -LN requirements were almost significantly fewer in the ELAPE group (OR 0.456, $\mathrm{P}=0.085)$. Among node-negative rectal cancers, significantly fewer resections failed the 12-LN standard in the ELAPE group than APR group (OR 0.211, $P=0.044)$. ELAPE led to a near-significant decrease in CRM involvement (OR 0.365, $P=0.088)$. These improvements were persistently observed after taking into account baselines and potential confounders in regression analyses.
\end{abstract}

Conclusion: ELAPE provides higher quality of LN harvests that meet the 12-minimal requirements than conventional APR, particularly in node-negative rectal cancers. The superiority is independent of potential confounding factors, and may implicate better clinical outcomes.

Keywords: Rectal cancers, Abdominoperineal excisions, Lymph nodes

\section{Background}

Abdominoperineal resections (APR) are the established curative surgical treatment for low rectal cancers within $4 \mathrm{~cm}$ from the anal verge [1]. A high rate of intraoperative bowel perforation (IBP) and risks of positive circumferential resection margin (CRM), both strong predictors of survival [2] had been reported to be as high as $30.4 \%$ in the Dutch TME trial [3] and 30.2\% in the MERCURY

\footnotetext{
*Correspondence: Ben.Liu@nhs.net
}

Department of General Surgery, New Cross Hospital, The Royal

Wolverhampton NHS Trust, Wolverhampton Road, Wolverhampton WV10

OQP, West Midlands, UK trial [4]. These have subsequently been correlated with higher recurrence rates and reduced survival after APR [5]. Extralevator Abdominoperineal Excision (ELAPE) had been described to standardise a cylindrical specimen without a "waist" in order to minimise CRM involvement, and early outcomes have been favourable [6-8]

In addition to CRM, the identification of lymph node (LN) metastases following surgical resection for colon and rectal cancer is well recognised as a key prognostic factor [9], and is a pre-requisite in accurate cancer staging [10]. Established evidence had demonstrated strong association between higher total LN counts and improved disease survival $[11,12]$ particularly for node 
negative colorectal cancers $[12,13]$. The presence of LN metastasis determines those most likely to benefit from adjuvant therapies as shown in multiple key phase III trials including the MOSAIC trial [14]. Although there are still debates regarding the optimal number of LNs required for adequate staging [15], the evaluation of at least $12 \mathrm{LNs}$ following colorectal resection is widely recommended in most clinical guidelines [16, 17]

It is not well understood how ELAPE may have an impact on recurrences and disease survival. The aim of our observational study therefore is to investigate differences in the number of lymph nodes yielded from ELAPE compared with conventional APR, which may be contributory to improvement in clinical outcomes. Evidence had shown diminishing returns from excessive lymph node dissection beyond the recommended 12 lymph nodes [18], our study hence focuses on whether ELAPE may be superior at meeting the $12 \mathrm{LN}$ minimal requirement.

\section{Methods}

\section{Study objectives}

The primary objective of this observational study is to determine if ELAPE improves the number of LN yield and the success of meeting the 12LN minimal requirement, compared with standard APR. The secondary objective is to compare the CRM involvement rates and determining whether the known advantages of ELAPE can be reproduced in a district general hospital setting.

The null hypothesis is finding no differences in the pathological outcomes between the two groups (ELAPE vs. APR). We evaluate whether any significant differences are independent of patients' baseline characteristics and other cofounders including the use of open / laparoscopic surgery and neoadjuvant chemoradiotherapy.

\section{Endpoints}

The primary endpoints are:

- Absolute number of lymph node yields

- Failure rates to meet the $12 \mathrm{LN}$ nodes pathological requirement

- Failure rates to meet the $12 \mathrm{LN}$ pathological requirement in node-negative (N0) subgroups

The secondary endpoint is.

\section{- The rates of CRM involvement}

From the register of this single centre, we included patients who underwent the two techniques of abdominoperineal resections for distal (low) rectal cancers (i.e. adenocarcinoma) over a 10 year period between 2009 and 2019.
Patients undergoing revisional or completion procedures or procedures for non-adenocarcinomas were excluded.

\section{Data collection}

Two groups of 30 consecutive cases were sampled over three years period before and after our adoption of ELAPE. Case notes were retrospectively reviewed for baseline characteristics including patients' age and sex. The operation notes were reviewed to determine the techniques employed and the types of access (open or laparoscopic). The uses of neoadjuvant therapies were documented.

\section{Statistics}

The UK Kingdom National Bowel Cancer Audit [17] showed a median of $15.1 \mathrm{LN}$ harvested from rectal resections, and $78.6 \%$ of them achieved the $12 \mathrm{LN}$ minimum. Shen et al. [19]in 2009 noted the mean number of LN ranges from 13.6 to 19 ; the standard deviation was 10.5 . Based on this data, at the power of $80 \%$ the minimum sample size for capturing a $5 \%$ difference between the two groups is 60.

Mann-Whitney $U$ Test was used to detect any significant differences in the absolute $\mathrm{LN}$ yield. Odds ratios were used to analyse differences in the rate of specimens failing the minimum $12-\mathrm{LN}$ requirement between the two groups. The same is applied to rates of CRM involvement. Regression analyses were used to detect differences between the two groups independently of potential confounders (baseline characteristics, laparoscopic/open surgery and the use of neoadjuvant therapies).

Missing data were minimal as we histological data is systematically gathered through our electronic system. If any were to arise, intention to treat analyses would be performed.

\section{Results}

After excluding 7 patients from the APR group and 3 patients from the ELAPE group according to our exclusion critera, there are 30 patients per study group included in the analyses. The exclusions are described in the flow diagram (Fig. 1).

\section{Baseline characteristics}

The baseline characteristics are shown in Table 1. There is no statistical difference in the genders and ages of patients between the two groups. Significantly fewer traditional APR cases (4/30) were performed laparoscopically compared with the ELAPE group $(11 / 30) \mathrm{P}=0.037$. There were no significant differences in the number of patients receiving neoadjuvant therapies between the two groups. 


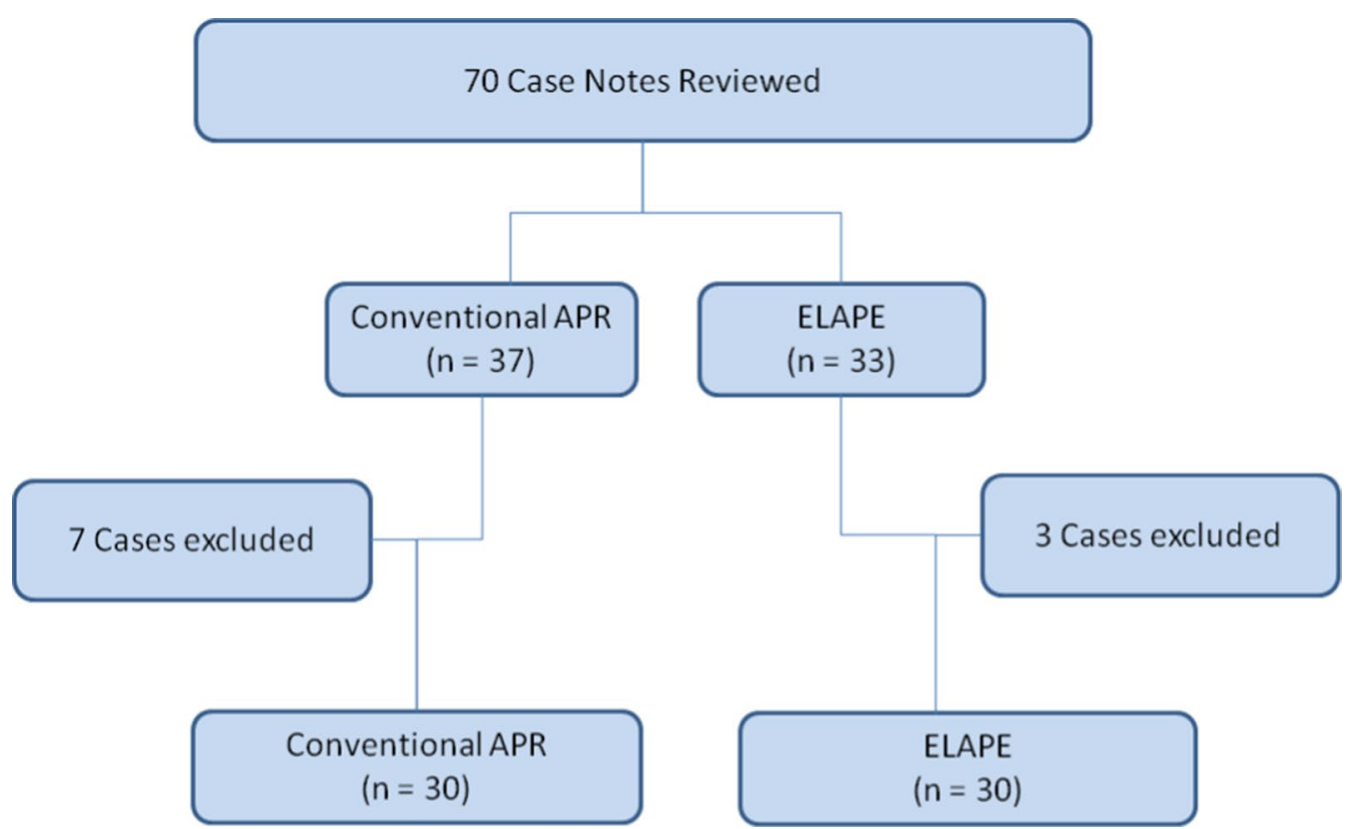

Fig. 1 Flow chart of case selection for the ELAPE and APR groups

Table 1 Baseline characteristics of the ELAPE and APR groups

\begin{tabular}{llll}
\hline & $\begin{array}{l}\text { Conventional } \\
\text { APR }\end{array}$ & ELAPE & P value \\
& $22: 8$ & $17: 13$ & 0.176 \\
Male:Female & 67.8 & 68.0 & 0.930 \\
Age & $4: 26$ & $11: 19$ & 0.037 \\
Laparoscopic:open surgery & $14 / 30$ & $16 / 30$ & 0.606 \\
Neoadjuvant chemoradiotherapy & 140 & & \\
\hline
\end{tabular}

\section{Lymph node counts}

The median number of lymph node harvested from conventional APR and ELAPE specimens were 15 and
16.5 respectively (Table 2) without significant differences between them $(P=0.181)$. The ELAPE group has lower rates of lymph node harvests failing the minimum 12 requirement $(7 / 30)$ compared with the conventional APR group (13/30), with odds ratio of 0.456 which almost reached statistical significance $(P=0.085)$. In those patients with negative nodal metastases status (N0), the rate of failing the $12-\mathrm{LN}$ requirement is significantly reduced (3/19) in the ELAPE group compared with the APR group (8/17), with odds ratio of 0.211 $(\mathrm{P}=0.025)$. When comparing the rates of pathological CRM involvement in the specimens, ELAPE (3/30) outperforms conventional APR (7/30) with odds ratio of 0.365 , which almost reached statistical significance $(\mathrm{P}=0.088)$.

Table 2 Comparisons of pathological results between the ELAPE group and APR group

\begin{tabular}{|c|c|c|c|c|c|}
\hline & $\begin{array}{l}\text { Median total lymph nodes } \\
\text { (LN) }\end{array}$ & Below $12 \mathrm{LN}$ requirement & $\begin{array}{l}\text { Node negative (N0), } \\
<12 \mathrm{LN} \text { requirement }\end{array}$ & CRM involvement & $\begin{array}{l}\text { Total } \\
\text { number } \\
\text { of cases }\end{array}$ \\
\hline ELAPE & 16.5 & $7 / 30$ & $3 / 19$ & $3 / 30$ & 30 \\
\hline Conventional APE & 15 & $12 / 30$ & $8 / 17$ & $7 / 30$ & 30 \\
\hline $\begin{array}{l}\text { Statistical tests and signifi- } \\
\text { cance }\end{array}$ & $\begin{array}{l}\text { Mann-Whitney U Test } \\
\quad(P=0.181)\end{array}$ & $\begin{array}{l}\text { Odds ratio (OR) } 0.456 \\
(\mathrm{P}=0.085) \\
(\mathrm{Cl} 0.149-1.396)\end{array}$ & $\begin{array}{l}\text { OR 0.211, } \\
P=0.025) \\
(C I 0.044-1.002)\end{array}$ & $\begin{array}{l}\text { OR 0.365, } \\
P=0.088) \\
(C l 0.085-1.576)\end{array}$ & 60 \\
\hline $\begin{array}{l}\text { Regression analysis (including } \\
\text { age, sex, lap/open, neoad- } \\
\text { juvants) }\end{array}$ & $P=0.224$ & $P=0.129$ & $P=0.044$ & $P=0.099$ & 60 \\
\hline
\end{tabular}




\section{Regression analyses}

There were no significant independent differences between the two groups in the median lymph node counts $(P=0.224)$, the rate of failure to reach $12 \mathrm{LN}$ $(\mathrm{P}=0.129)$ and the rates of $C R M$ involvement $(\mathrm{P}=0.099)$. However in those with nodal negative status (N0), significantly lower failure rates of harvesting $12 \mathrm{LN}$ minimum were consistently observed $(\mathrm{P}=0.044)$ in the ELAPE group, which is independent of the aforementioned confounders.

\section{Discussion}

In this study we have compared lymph nodes harvests from ELAPE and conventional APR. The median number of LN yielded from conventional APR is 15 , which is the same number as those reported from 69 retrospective cases by Shen et al. 2009 [19]. The media LN count of 16.5 in our ELAPE group is slightly higher than the APR group, and is comparable to the median of 13.7 nodes from a large scale $(n=519)$ Swedish population study on ELAPE [20]. Neither our study nor the Swedish cohorts found significant differences between APR and ELAPE groups. However, reported number of $\mathrm{LN}$ harvest from APRs in literature varies greatly. In general LN counts for abdominoperineal excisions are lower than other type of colorectal resections, and as low as $9 \mathrm{LN}$ were reported [21]. The number of lymph nodes harvested at our unit appears higher compared to most literature. This may be explained by the contemporaneousness of our data, with higher proportions of laparoscopic surgery compared with established evidence. Dolan et al. [22], in a prospective study of 896 patients spanning 20 years (1997-2016), had found significant independent correlation between later operative date, increasing prevalence of laparoscopic surgery and higher lymph node harvests.

\section{2-LN minimal requirement}

Secondly, we noticed a reduction in the rate of resections failing to meet the 12-LN minimal requirement under the ELAPE technique compared with traditional APR. The differences are considerable and almost statistically significant. There is a paucity of evidence from the literature comparing the adequacy of LN harvests between abdominoperineal excision techniques despite emphases of its importance by many authors [13, 23-25] and guidelines from National Cancer Institute [16]. A minimum of 12 lymph nodes was recommended [23] as below this cut-off value there is a high risk of false-negatives in reporting lymph node metastases due to inadequate sampling [25]. The 12-node standard has been endorsed by other researches for reasons of "diminishing returns" beyond the examination of 12-17 nodes [18]. In our study, $60 \%$ and $77 \%$ of specimens in the APR and ELAPE groups respectively met this standard. When compared with results from authors who specifically investigated the 12-LN standard among rectal cancers, our cohort of patients have achieved higher rates of success in general. Field et al. [21] reported 50\%, while Gurawalia et al. [26] achieved 52\%, and Baxter et al. [27] had a $46.4 \%$ attainment rate. Our higher success rate could be explained again by the contemporaneousness of our cases and prevalence of laparoscopic surgery, both considered independent determinants of meeting the $12-\mathrm{LN}$ standard [22]

\section{Node negative disease}

British reviewers Ong and Schofield [28] have summarised that node-negative colorectal cancer patients have a 5 -year survival rate of $70-80 \%$ in contrast to $30-60 \%$ for their nodal-positive counterparts. Survival can be improved in the latter group by adjuvant chemotherapy [14]. The $20-30 \%$ disease recurrence in apparently completely excised tumours without LN metastases is thought to be due to occult LN disease [29]. If this subset of patients could be identified by better lymph node staging, they may then benefit from adjuvant chemotherapy. Nodal-positive resections, irrespective of the number of LN harvested, would indicate adjuvant chemotherapy. Therefore substantial researches have focused on the accuracy of nodal staging and prognosis among nodenegative individuals, in whom adequacy of LN harvests bears greater prognostic value [12, 30,31]. We have similarly conducted a separate analysis on nodal-negative cases to determine whether the minimum 12-LN standard was met in this subset. We have found significantly lower rates of failures in meeting the requirement among the ELAPE group compared with APRs. This suggests that ELAPE may be superior at minimising false-negatives in apparent node-negative diseases, leading to more appropriate staging and decision-making on adjuvant treatments. The mechanism underlying our observation is not entirely understood, since anatomically the mesorectum tapers and diminishes as it adjoins the pelvic floor. However as Holms et al. eluded to in their paper [6], while other techniques (e.g. intersphincteric, extrasphincteric dissections) exist, ELAPE offers a standardised approach in abdominoperineal excisions, leading to more consistent quality of resections that in turn reduces substandard Total Mesorectal Excisions (TME)s.

\section{CRM involvement}

The overall CRM rate of our cohort is $16.7 \%$, which is relatively high but comparable to published data of $16.6 \%$ from Great Britain [32] and 16.7\% from Canada [33]. Our study has showed a decreased rate of CRM involvement among the ELAPE group compared with conventional 
APR, though not reaching a statistically significant level. Several studies $[20,34,35]$ have similarly failed to show significant superiority of ELAPE in CRM clearance. Among them, the Danish study on ELAPE [35] suggests a magnitude of CRM+ve reduction (OR 0.386) that is comparable to our data (OR of 0.365). The more recent, yet small $(\mathrm{n}=34)$ randomised controlled trial (RCT), nevertheless, demonstrated a significantly improved CRM in their ELAPE arm [36]. Our investigation suggests that this apparent benefit of ELAPE may be reproducible in a district general hospital setting among 8 colorectal surgeons at our unit.

\section{Potential confounders}

The quality of surgery is undoubtedly a major determinant of LN harvests [37, 38]. However, other clinicopathologic factors may also influence lymph node retrievals. In particular, studies have demonstrated significant reductions in the mean $\mathrm{LN}$-yields among patients who received neoadjuvant chemoradiotherapy-from 17 to 13 [39], and from 19 to 16 [40]. Other authors including Field et al. [21] have found young, female patients and higher $\mathrm{T}$ stages of cancers to correlate with higher $\mathrm{LN}$ yield. There were also significant links between laparoscopic surgery and higher rate of succeeding the 12-LN standard [22]. On this basis, we have conducted regression analyses taking into account the above predictors of LN yield as potential confounders. This has not changed the correlations found in our results. The rate of failure to achieving 12LN standard remains significantly lower in the ELAPE group among the nodal negative cohorts. The reduction in CRM involvement is still present but not statistically significant. Our analyses have suggested the superiority of ELAPE to be independent of these factors.

\section{Limitations}

As a retrospective observational study, our investigation is subject to the usual limitations of selection and recall biases. The aim of our research was to establish whether ELAPE leads to a better pathological results. We have yet to establish whether this would necessarily translate to an improvement in clinical outcomes i.e. local recurrence rate (LR) and disease survival. Several systematic reviews on ELAPE found no improvement in either CRM or LR [34, 41]. Some mata-analyses [42] showed that despite ELAPE significantly lowering the rates of CRM involvement, it did not lead to subsequent benefits in the LR, while others [42], to the contrary, did demonstrate a significant reduction in LR (OR 0.30, $\mathrm{P}<0.01)$. Even if the LR were found to be improved with ELAPE, some authors had found no difference in survival or disease progression in both a prospective study
[43] a randomised controlled trial with median followup of 20 months [44]. However these studies have been marred by their small recruitment numbers $(n=69$ and $\mathrm{n}=67$ respectively) and short follow-up periods.

Less disputable, nevertheless is evidence that a larger number of lymph nodes retrieved lead to a survival advantage [30]. This was initially attributed to upstaging cases of "missed" positive lymph nodes. However, more recent studies suggest that this phenomenon cannot be explained by staging migration alone. A systematic review [18] found improved survivals correlating with higher lymph node harvests in stage-III as well as stage-II diseases. Furthermore, lymph node sampling past a certain point does not appear to improve disease staging [45]. Interestingly Joseph et al. [46] found that better LN harvests improve cancer survival irrespective of patients' nodal statuses (N1 or N0). Tumour-host interactions may be a plausible explanation for this, as higher LN yield may reflect a stronger host immune response [47].

Our results had lacked pathological reporting of the lengths of our specimens. This may be because there has not been a standardised length of resection for APRs in general. The amount of mesentery associated with specimen length undoubtedly correlates with the number of LNs found [19] and therefore a potential source of bias. Despite our effort to improve LN harvests, no internationally recognised standards of practice have been developed for the histopathological processing of lymph nodes in specimens [48]. A notable Canadian study showed that only $58 \%$ of pathologists were aware of current guidelines and that only $25 \%$ recognized that a minimum of 12 LNs was necessary for accurate designation of node negativity [49]. The potentially variable attentivenss and experience among out pathologists may be a source of bias. Similarly the different experiences among our 9 colorectal surgeons who perform APERS/ELAPE may also have contributed to the observed differences between the two study groups. The apparent advantages of ELAPE need to be balanced with its associated morbidity. Authors have reported significantly greater post-operative wound infections after ELAPE (20.5\%) than for APR (12\%) [20]. A prospective multicentred trial [50] also suggested higher rates of sexual dysfunction, urinary retention, and perineal complications associated with ELAPE. On contrary, a meta-analysis [51] found no differences in complication rates between the techniques, and some of these complications can be mitigated with reconstructions using meshes or plastic surgery. Regardless, our enthusiasm for ELAPE should always be tempered with caution and consideration of its higher complexity and potential morbidity. 


\section{Conclusion}

The findings of our comparative study has concluded that ELAPE is conducive to superior lymph node harvests particularly in regards to achieving the 12 lymph node requirement for accurate staging and appropriate adjuvant treatment of rectal cancer, and especially in apparently node negative rectal cancers. The outcome is independent of several known factors that can affect lymph node counts. A CRM+ve reduction was also deemed reproducible in a district general hospital setting. The long-term clinical outcomes in terms of recurrences and survival are still to be determined by large multicentre RCTs, which will also serve to confirm the main results of this retrospective study.

\section{Abbreviations}

APR: Abdominoperineal resections; CRM: Circumferential resection margin; ELAPE: Extralevator abdominoperineal excisions; IBP: Intraoperative bowel perforation; LN: Lymph node; LR: Local recurrence; RCT: Randomised controlled trial; TME: Total mesorectal excision.

\section{Acknowledgements}

Not applicable.

\section{Authors' contributions}

BL: Chief Investigator, case identification, data collection, data analyses, main author. JF: Sub-investigator, data collection, data analyses, co-author. All authors have read and approved the manuscript.

\section{Funding}

No additional source of funding was sought or given.

\section{Availability of data and materials}

The datasets used and analysed during the current study are available from the corresponding author on reasonable request.

\section{Ethics approval and consent to participate}

Written informed consents have been obtained from the study subjects. Data were collected, processed and stored in accordance with the Data Protection Act. The study protocol was submitted and approved by Research Ethics Committee via Health Research Authority (UK) IRAS reference ID: 282958.

\section{Consent for publication}

Not applicable.

\section{Competing interests}

The authors declare that they have no competing interests.

Received: 11 May 2020 Accepted: 7 October 2020

Published online: 16 October 2020

\section{References}

1. Perry WB, Connaughton JC. Abdominoperineal resection: how is it done and what are the results? Vol. 20, Clinics in colon and rectal surgery. New York: Thieme Medical Publishers; 2007. p. 213-20.

2. Bernstein TE, Endreseth BH, Romundstad P, Wibe A. Circumferential resection margin as a prognostic factor in rectal cancer. Br J Surg. 2009:96(11):1348-57.

3. Nagtegaal ID, Van De Velde CJH, Marijnen CAM, Van Krieken JHJM, Quirke P. Low rectal cancer: a call for a change of approach in abdominoperineal resection. J Clin Oncol. 2005;23(36):9257-64.
4. Taylor FGM, Quirke P, Heald RJ, Moran BJ, Blomqvist L, Swift IR, et al. Preoperative magnetic resonance imaging assessment of circumferential resection margin predicts disease-free survival and local recurrence: 5-year follow-up results of the MERCURY study. J Clin Oncol. 2014;32(1):34-43. https://doi.org/10.1200/JCO.2012.45.3258.

5. Hussain A, Mahmood F, Torrance ADW, Clarke H, Howitt C, Dawson R. Oncological outcomes of abdominoperineal resection for the treatment of low rectal cancer: a retrospective review of a single UK tertiary centre experience. Ann Med Surg. 2018;1(34):28-33.

6. Holm T, Ljung A, Häggmark T, Jurell G, Lagergren J. Extended abdominoperineal resection with gluteus maximus flap reconstruction of the pelvic floor for rectal cancer. Br J Surg. 2007;94(2):232-8.

7. West NP, Finan PJ, Anderin C, Lindholm J, Holm T, Quirke P. Evidence of the oncologic superiority of cylindrical abdominoperineal excision for low rectal cancer. J Clin Oncol. 2008;26(21):3517-22.

8. De Nardi P, Summo V, Vignali A, Capretti G. Standard versus extralevator abdominoperineal low rectal cancer excision outcomes: a systematic review and meta-analysis. Annals of surgical oncology, vol. 22. New York: Springer; 2015. p. 2997-3006.

9. Baxter NN, Virnig DJ, Rothenberger DA, Morris AM, Jessurun J, Virnig BA. Lymph node evaluation in colorectal cancer patients: a population-based study. J Natl Cancer Inst. 2005:97(3):219-25.

10. Morris EJA, Maughan NJ, Forman D, Morris E, House A. Who to treat with adjuvant therapy in Dukes B/stage II colorectal cancer? The need for high quality pathology. Gut. 2007;56:1419-25.

11. Caplin S, Cerottini JP, Bosman FT, Constanda MT, Givel JC. For patients with Dukes'B (TNM Stage II) colorectal carcinoma, examination of six or fewer lymph nodes is related to poor prognosis. Cancer. 1998:83(4):666-72.

12. Tepper JE, O'Connell MJ, Niedzwiecki D, Hollis D, Compton C, Benson AB, et al. Impact of number of nodes retrieved on outcome in patients with rectal cancer. J Clin Oncol. 2001;19(1):157-63.

13. McDonald JR, Renehan AG, O'Dwyer ST, Haboubi NY. Lymph node harvest in colon and rectal cancer: current considerations. World J Gastrointest Surg. 2012;4(1):9-19.

14. André T, Boni C, Navarro M, Tabernero J, Hickish T, Topham C, et al. Improved overall survival with oxaliplatin, fluorouracil, and leucovorin as adjuvant treatment in stage II or III colon cancer in the MOSAIC trial. J Clin Oncol. 2009;27(19):3109-16.

15. Wong SL. Lymph node counts and survival rates after resection for colon and rectal cancer. Gastrointest Cancer Res. 2009;3(2 Suppl):S33-5.

16. Nelson H, Petrelli N, Carlin A, Couture J, Fleshman J, Guillem J, et al. Guidelines 2000 for colon and rectal cancer surgery. J Natl Cancer Inst. 2001;93(8):583-96.

17. Smith JJ, Finan PJ. National Bowel Cancer Audit 2009 [Internet]. 2009. https://files.digital.nhs.uk/publicationimport/pub02xxx/pub02587/naticlin-audi-supp-prog-bowe-canc-2009-rep2.pdf

18. Chang GJ, Rodriguez-Bigas MA, Skibber JM, Moyer VA. Lymph node evaluation and survival after curative resection of colon cancer: systematic review. J Natl Cancer Inst. 2007;99(6):433-41.

19. Shen SS, Haupt BX, Ro JY, Zhu J, Bailey HR, Schwartz MR. Number of lymph nodes examined and associated clinicopathologic factors in colorectal carcinoma. Arch Pathol Lab Med. 2009:133(5):781-6.

20. Prytz M, Angenete E, Ekelund J, Haglind E. Extralevator abdominoperineal excision (ELAPE) for rectal cancer - Short-term results from the Swedish Colorectal Cancer Registry. Selective use of ELAPE warranted. Int J Colorectal Dis. 2014:29(8):981-7.

21. Field K, Platell C, Rieger N, Skinner I, Wattchow D, Jones I, et al. Lymph node yield following colorectal cancer surgery. ANZ J Surg. 2011:81(4):266-71.

22. Dolan RD, McSorley ST, Horgan PG, McMillan DC. Determinants of lymph node count and positivity in patients undergoing surgery for colon cancer. Medicine (Baltimore). 2018;97(13):e0185.

23. Fielding LP, Arsenault PA, Chapuis PH, Dent O, Gathright B, Hardcastle JD, et al. Clinicopathological staging for colorectal cancer: An International Documentation System (IDS) and an International Comprehensive Anatomical Terminology (ICAT). J Gastroenterol Hepatol. 1991;6(4):325-44.

24. Serrano M, Biondo S. Abdominoperineal excision or extralevator abdominoperineal excision: which is the best oncological treatment? Ann Laparosc Endosc Surg. 2018;3:4. 
25. Vather R, Sammour T, Kahokehr A, Connolly A, Hill A. Quantitative lymph node evaluation as an independent marker of long-term prognosis in stage III rectal cancer. ANZ J Surg. 2011;81(12):883-8.

26. Gurawalia J, Dev K, Nayak SP, Kurpad V, Pandey A. Less than 12 lymph nodes in the surgical specimen after neoadjuvant chemo-radiotherapy: an indicator of tumor regression in locally advanced rectal cancer? J Gastrointest Oncol. 2016;7(6):946-57.

27. Baxter NN, Ricciardi R, Simunovic M, Urbach DR, Virnig BA. An evaluation of the relationship between lymph node number and staging in pT3 colon cancer using population-based data. Dis Colon Rectum. 2010;53(1):65-70.

28. Ong MLH, Schofield JB. Assessment of lymph node involvement in colorectal cancer. World J Gastrointest Surg. 2016:8(3):179.

29. Nicastri DG, Doucette JT, Godfrey TE, Hughes SJ. Is occult lymph node disease in colorectal cancer patients clinically significant? A review of the relevant literature. J Mol Diagn. 2007;9:563-71.

30. Swanson RS, Compton CC, Stewart AK, Bland KI. The prognosis of T3NO colon cancer is dependent on the number of lymph nodes examined. Ann Surg Oncol. 2003;10(1):65-71.

31. Le Voyer TE, Sigurdson ER, Hanlon AL, Mayer RJ, Macdonald JS, Catalano PJ, et al. Colon cancer survival is associated with increasing number of lymph nodes analyzed: a secondary survey of intergroup trial INT-0089. J Clin Oncol. 2003;21(15):2912-9.

32. Xanthis A, Greenberg D, Jha B, Olafimihan O, Miller R, Fearnhead N, et al. Local recurrence after "standard" abdominoperineal resection: do we really need ELAPE?

33. Messenger DE, Cohen Z, Kirsch R, O'Connor BI, Victor JC, Huang H, et al. Favorable pathologic and long-term outcomes from the conventional approach to abdominoperineal resection. Dis Colon Rectum. 2011;54(7):793-802.

34. Ortiz H, Ciga MA, Armendariz P, Kreisler E, Codina-Cazador A, GomezBarbadillo J, et al. Multicentre propensity score-matched analysis of conventional versus extended abdominoperineal excision for low rectal cancer. Br J Surg. 2014;101(7):874-82.

35. Klein M, Fischer A, Rosenberg J, Gögenur I. ExtraLevatory AbdominoPerineal Excision (ELAPE) does not result in reduced rate of tumor perforation or rate of positive circumferential resection margin: a nationwide database study. Ann Surg. 2015;261(5):933-8.

36. Bianco F, Romano G, Tsarkov P, Stanojevic G, Shroyer K, Giuratrabocchetta $S$, et al. Extralevator with vs nonextralevator abdominoperineal excision for rectal cancer: the RELAPe randomized controlled trial. Color Dis. 2017;19(2):148-57.

37. Rieger NA, Barnett FS, Moore JWE, Ananda SS, Croxford M, Johns J, et al. Quality of pathology reporting impacts on lymph node yield in colon cancer. J Clin Oncol. 2007;25:463.

38. Evans MD, Barton K, Rees A, Stamatakis JD, Karandikar SS. The impact of surgeon and pathologist on lymph node retrieval in colorectal cancer and its impact on survival for patients with Dukes'stage B disease. Color Dis. 2008;10(2):157-64.
39. Rullier A, Laurent C, Capdepont M, Vendrely V, Belleannée G, Bioulac-Sage $P$, et al. Lymph nodes after preoperative chemoradiotherapy for rectal carcinoma: number, status, and impact on survival. Am J Surg Pathol. 2008;32(1):45-50

40. Morcos B, Baker B, Al Masri M, Haddad H, Hashem S. Lymph node yield in rectal cancer surgery: effect of preoperative chemoradiotherapy. Eur J Surg Oncol. 2010;36(4):345-9.

41. Zhou X, Sun T, Xie H, Zhang Y, Zeng H, Fu W. Extralevator abdominoperineal excision for low rectal cancer: a systematic review and meta-analysis of the short-term outcome. Color Dis. 2015;17(6):474-81.

42. Zhang Y, Wang D, Zhu L, Wang B, Ma X, Shi B, et al. Standard versus extralevator abdominoperineal excision and oncologic outcomes for patients with distal rectal cancer: a meta-analysis. Medicine (Baltimore). 2017:96(52):e9150.

43. Shen Z, Ye Y, Zhang $X$, Xie Q, Yin M, Yang X, et al. Prospective controlled study of the safety and oncological outcomes of ELAPE procure with definitive anatomic landmarks versus conventional APE for lower rectal cancer. Eur J Surg Oncol. 2015;41(4):472-7.

44. Han JG, Wang ZJ, Wei GH, Gao ZG, Yang Y, Zhao BC. Randomized clinical trial of conventional versus cylindrical abdominoperineal resection for locally advanced lower rectal cancer. Am J Surg. 2012;204(3):274-82.

45. Denham $\sqcup$, Kerstetter JC, Herrmann PC. The complexity of the count: considerations regarding lymph node evaluation in colorectal carcinoma. J Gastroint Oncol. 2012;3:342-52.

46. Joseph NE, Sigurdson ER, Hanlon AL, Wang H, Mayer RJ, MacDonald JS, Catalano PJ, Haller DG. Accuracy of determining nodal negativity in colorectal cancer on the basis of the number of nodes retrieved on resection. Ann Surg Oncol. 2003;10(3):213-8.

47. Dawson $H$, Kirsch $R$, Messenger D, Driman D. A review of current challenges in colorectal cancer reporting. Arch Pathol Lab Med. 2019;143:869-82

48. Simunovic M, Baxter NN. Lymph node counts in colon cancer surgery: lessons for users of quality indicators. JAMA. 2007;298(18):2194-5.

49. Wright FC, Law CHL, Last LD, Ritacco R, Kumar D, Hsieh E, et al. Barriers to optimal assessment of lymph nodes in colorectal cancer specimens. Am J Clin Pathol. 2004;121(5):663-70.

50. Wang Z, Qian Q, Dai Y, Zhang Z, Yang J, Li F, et al. A prospective multicenter clinical trial of extralevator abdominoperineal excision for locally advanced low rectal cancer. Zhonghua Wai Ke Za Zhi. 2014;52(1):11-5.

51. Chen Y, Chi P. Meta-analysis of extralevator abdominoperineal excision for rectal cancer. Zhonghua Wei Chang Wai Ke Za Zhi. 2017;20(3):326-32.

\section{Publisher's Note}

Springer Nature remains neutral with regard to jurisdictional claims in published maps and institutional affiliations.
Ready to submit your research? Choose BMC and benefit from:

- fast, convenient online submission

- thorough peer review by experienced researchers in your field

- rapid publication on acceptance

- support for research data, including large and complex data types

- gold Open Access which fosters wider collaboration and increased citations

- maximum visibility for your research: over $100 \mathrm{M}$ website views per year

At BMC, research is always in progress.

Learn more biomedcentral.com/submissions 